\title{
The Impact of Meteobaroconditioning on the Parameters of Psycho-physiological State of Students Using Information and Communication Technologies
}

\author{
Sergey Ryagin \\ Doctor of Pedagogical Sciences, Professor, Deputy Director in Science, \\ Institute of Education Management of the Russian Academy of Education, Moscow, Russia \\ ryagin_sn@mail.ru \\ Iskandar Mukhametzyanov \\ Doctor of Medical Sciences, Professor, Chief Researcher, \\ Institute of Education Management of the Russian Academy of Education, Moscow, Russia \\ ishm@inbox.ru \\ Alla Dimova \\ Candidate of Pedagogical Sciences, Leading Researcher, \\ Institute of Education Management of the Russian Academy of Education, Moscow, Russia \\ adimova@mail.ru
}

\section{Doi:10.5901/mjss.2015.v6n6s5p160}

\begin{abstract}
An inevitable result of the education intensification, its wide informatization and its going out beyond the educational institutions is the progressive reduction of students' health. The educational activities of students outside the institution are currently not controlled by the education authorities, which necessitates not only developing the culture of using the modern information and communication technologies beyond the educational institution in students, but also developing the rehabilitation system for them. The system has to be a controlled one and, therefore, included in the educational process within the educational institution. The paper examines the techniques of meteobaroconditioning which allows ensuring prevention and treatment of meteorotropic reactions based on applying pulse barotraining in condition of day-to-day fluctuations of atmospheric pressure in order to form individually developed protective and adaptive reactions of a "drilling" kind oriented to enhancing the organism resistance and curtailing the pathological reactions.
\end{abstract}

Keywords: information and communication technologies; rehabilitation; meteobaroconditioning; meteobarotent.

\section{Introduction}

Under consistent change of the Russian Federation continuous education, the problem of maintaining and restoring the health of general education students is becoming increasingly important [2]. The problem gains especial importance due to active introduction of the modern information and communication technologies (ICT) into the academic process, the studying itself going beyond the controlled educational space of an educational institution into the non-controlled space of the learners' stay, and the considerable intensification of the academic process as such [7].

The preventive health care existing within the framework of the comprehensive educational organization is focused on reducing the overall diseases incidence and rehabilitation of students' physical activity. However, the mass-scale use of modern ICT largely changes the traditional microclimate of classrooms making them similar to that of the office space.

Given the above, it seems interesting to consider the opportunities for correcting the negative consequences of ICT tools use within the developed by us technique of meteobaroconditioning which so early as after the first application allows exercising a wide range of therapeutic and training influence on students' organisms.

\section{Literature Review}

The modern period of the global educational space development in recent years is characterized by a significant increase in the impact of ICT on students, due to the educational organization and its use, both within the institution and outside it in places of students' residence or their location area (in the information and educational space). In particular, the 
intensification of such exposure gives rise to an increase in the number of all possible negative consequences for the health of students, users of ICT which are marked by a number of Russian and foreign specialists (Muchamedzyanov, 2010; Frazier, 2015; Thomée et al., 2015).

Russian experts in the field of medicine, psychology, informatization of education, and others, note that the use of ICT in everyday life and the learning process of educational institutions leads to various diseases of users of the main systems of vital functions of the human body: the locomotor, cardiovascular, visual, respiratory and nervous system. Among the most common diseases observed, there are the following: spinal curvature in its various regions and development of osteochondrosis; shortsightedness and farsightedness; hypertension and hypotension; stress, insomnia, depression, and others. The research of K. Frazier (Frazier, 2015) showed that the use of social networks for more than 3 hours a day with a large number of messages (over 120 text messages a day) were correlated with unhealthy behaviors of students. There is also a trend to depression, insomnia; suicidal behavior is observed, alongside with poor performance and low state of health.

One of the causes of poor efficiency of the proposed by I.Sh. Mukhametzyanov, I.V. Robert and others are preventive means and organizational measures among which the central place is occupied by integral hygiene requirements for personal computers and organization of work with them is that these organizational and methodological activities are aimed only at preventing the possible negative effects of ICT use, but not at compensation thereof (Mukchametzyanov, 2010; Robert, 2008). The analysis also showed that these and other authors did not review the issues of development and use of measures oriented for the compensation of the identified adverse effects on the ICT users health in the learning process of educational institutions. It is necessary to take into account the negative impact of emotional stress on the students health (especially at the initial stage of learning). In the system of sport and recreational activities, considerable attention has to be paid to developing an integrated system of psycho-physiological support of educational and motor activity of students. However, such important issues remain unresolved as managing the students' bodies temporary adaptation during learning, recreation and recreational activities and psycho-physiological rehabilitation; adaptation to the effects of several environmental factors; adaptation of the organism to extreme stress situations; quantitative and qualitative assessment of the adaptation processes, etc.

At the same time the analysis of scientific literature showed that in Russia in recent years began to appear scientific researches on solving the problem of compensation of the negative impact of harmful factors of the educational environment on the health of students through the use of compensation (recovery) tools and techniques (Karpenko, 2003). As an example, we can study the level of air ionization in offices and classrooms completed with office equipment, central forced air purification and air-conditioning. The authors noted that the ion balance in the air with artificial climate is characterized by a pronounced shortage of light negative aeroions, which can be repleted only by using artificial air ionization. Also the main harmful factors which negatively affect the health of the ICT user in offices and classrooms were determined:

- staying in a seated position for a long time, which leads to neck, head, arms, shoulders, spine and muscle tension; osteochondrosis, overloading joints, stagnation of blood in the pelvic organs;

- increased eyestrain: visual fatigue leading to a general fatigue of the body, headaches, malfunction of the cardiovascular and nervous systems; reduced visual acuity, myopia, a "dry eye" syndrome;

- pronounced shortage of negative ions in the breathing zone of ICT users: aeroionic hunger, leading to headaches, fatigue, disorders of the nervous system and reduce the body defenses;

- air draught;

- prolonged exposure to electromagnetic fields generated by the elements of the computer;

- the loss of information stress: the nervous strain.

The above mentioned factors determine the use of appropriate compensation measures, which include: aerohydroionotherapy, bioresonance oftalmocolourtherapy, auditory training, meteobaroconditioning, vibration massage, magnetic therapy, the stimulation of the biological activity and some other means and methods. At the same time, under compensatory means we understand health treatments carried out with the help of technical equipment. Compensation measure is also positioned as a means of intensive recovery because it provides health benefits after the first application. This effect can be enhanced while using compensation measures which are compatible with each other.

According to the opinion of O.J Boxer, A.L. Dimova, L.G. Ulyaeva and others, the most universal compensatory means that possesses a wide range of health effects on the cardiovascular, nervous, respiratory and visual system of the patient is meteobaroconditioning (Dimova, 2012; Karpenko, 2003; Ulyaeva, 2013). Meteobaroconditioning is a technique elaborated by O.J. Boxer. It is a technique of pulse barotraining in condition of day-to-day fluctuations of atmospheric pressure for the prevention and treatment of meteorotropic reactions (Karpenko, 2003). The critical values causing 
pathological changes in human's body are the inter-day fluctuations in atmospheric pressure - approximately $\pm 8,5$ mbar. Due to this, a regular simulation of such conditions at the level of sub-threshold dose values of day-to-day atmospheric pressure fluctuations, and regularly recurring effects will form the individually developed protective and adaptive reactions of the "drilling" type in order to improve the organism resistance and to curtail the pathological reactions (Karpenko, 2003; Mandrykin, 2003).

There are well known methods of artificial regulation of atmospheric pressure elaborated for the purpose of training flight personnel, cosmonauts and climbers to the portability of large degrees of oxygen deficiency at high altitudes. These methods are implemented in the power of stationary pressure tents which were designed for the absolute values of the artificially formed pressure (which corresponds to 5,5-12 thousand meter heights. They are a hundred times higher than the value of sharp daily fluctuations in the atmospheric pressure). However, these methods do not provide prevention and treatment of elevated meteosensitivity. The O.J. Boxer's method differs from the prototype. Its purpose is to increase the body's resistance to fluctuations in atmospheric pressure and to provide non-pharmacological prevention of painful reactions of the organism in the run-up of the reliably predicted daily sharp drop of the atmospheric pressure. The goal set can be achieved by the process in which the person must be subjected twice a year, in early spring and autumn to daily (for one week) sessions of artificial fluctuations of atmospheric pressure in meteobarotent (MBC) lasting 15-30 minutes. Every 2 minutes the sub pressure is replaced by one minute of exposure to elevated pressure and vice versa, in a mode of $\pm 20 \mathrm{~mm}$. of mercury. The subject, during the rest of the year, 4-8 hours before the professionally projected natural change of pressure is exposed to a single artificial change of barometric pressure which depends on the decreasing or increasing prediction in the range of 15-30 of mercury with a speed of 0.5-1.0 mm of mercury.

For realization of the meteobarotrainings we used a special device which is called meteobarobath. Due to the studies we found out that the use of systematic impulse meteobarotrainings by students are characterized by high longterm efficiency, besides there is a good tolerability of single processes and the entire course. Meteobarotrainings reduce the number of meteorotropic reactions 2-3 times, and in some cases completely eliminate meteorotropic pathology. The highest rates are found in combination of meteobarotrainings with methods of psychoregulation (auditory training, biofeedback), and others. Studies have shown that after a prophylactic course in addition to the specific actions (meteosensitivity reducing) noted an increase in exercise tolerance, decrease (normalization) of blood pressure, optimization of the cardio respiratory system (Karpenko, 2003).

\section{Research Materials}

The created meteobaroset called "Meteobarotent" (by analogy with the well-known "oxygen tent" for the oxygen respiratory treatment) has a size sufficient for simultaneous training (treatment) at least of ten people, placed in a sitting position (shown in Figure 1). Its volume is $2700 \mathrm{m3}$. Meteobarotent has a streamlined form. The walls of its case consist of numerous transparent polygons, for example, made of glass or plexiglass of a certain thickness, each of them is bordered by a rigid frame, for example, plastic or metal one. Polygons hermetically joined with each other. This design, as shown by numerous experiments and tests, excludes the slightest walls deflections of the bulky case of the meteobarotent with decreasing or increasing air pressure inside it, even if the pressure is 5-6 times higher than requested ( $\pm 10 \mathrm{~mm}$. of mercury).

Inside the meteobarotent, a programmable device was used based on an industrial time relay connected to the compressor for automated slide-varying of duration and air pressure increase.

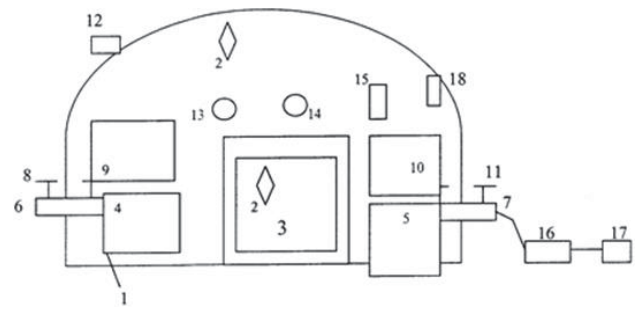

Figure 1. Diagram of the multiseater meteobarotent with programmable control

The meteobarotent has a streamlined body (1), its walls consist of numerous transparent polygons (2), bordered by rigid frames hermetically joined with each other, the door (3) with the elements of sealing at least two inner ones $(4,5)$ and two 
outer pipes $(6,7)$ which connect the bath cavity to the ambient atmosphere, the valves $(8,9,10,11)$ joined with the inner and outer nozzles, adjustable valve of the ultimate air pressure (12), means for measuring the air pressure (13), means for measuring the gradient (slope), differential pressure (variometer) (14), the communication device (15), the compressor (16), the programming unit (17), the internal switch of the programming unit and the compressor (18).

\section{Research Methods}

The organization of the group rehabilitation of students which use the ICT based on the meteobaroconditioning methods required creation of a multiseater meteobaroset. In our multiseater meteobarotent (A.L. Dimova, M.P. Karpenko, O.J. Boxer) was used the ventilation mode for the air outflow and inflow in the range of 8-10 mm of mercury (Karpenko, 2003).

Meteobarotent conveniently provides the mode when the "dry" meteobarotraining is required to combine with water treatments. With the sequential combination of "dry" and "water" training the last one is provided out of the meteobarotent.

If it is desirable to synchronize both modes, which is rare, and mostly when children are being trained, inside of meteobarotent is installed the portable container filled with water. In such case the number of persons simultaneously present in the meteobarotent is reduced in two or three times.

The sequence of the operations is the following. Some students (up to 10) enter the meteobarotent and sit down on the arcuate bench situated along the inner surface of the case. The door closes. The operator sets the programming unit to the desired mode of pulsating (air pressure lowering-increasing) meteobarotraining and with the help of the programming unit turns on the compressor. At the end of the programmed time (15-30 minutes) programming unit and the compressor is being switched off, the students leave the case. Meteobarotent functions in the ventilation mode, which is provided by relative sealing. This sets the external air suction mode (output of the inner air) of the meteobarotent approximately 2 liters/min (controlled by variometer). Research and practice have shown that such a relative hermetic sealing, providing ventilation, doesn't practically prevent the required air pressure within the meteobarotent. The valves 8 and 9 can be used as regulators of air suction and air release.

The programming unit of the multiseater meteobarotent (PU MSMBT) is based on the time relay type PB BAR (T3). This special purpose device is intended for pulse switching of the inductive or mixed load of power devices charged from a household outlet and used to service the multiseater meteobarotent. The programming unit provides the meteobarotent start in different modes both by the operator and on the pre-selected temporary installation and provides an independent changing by operator the parameters of the pulse sequence generated by the device.

The PU MSMBT is based on the modern microprocessor which controls the specialized chip real-time clock and work out algorithms for switching the light load in accordance with the program. The presence of the timer chip of the lithium battery provides the functioning of the internal clock and storage of algorithm control parameters, even in case of power failure or cut. Even if the unit does not receive any power supply, for example, it is stored in the warehouse; the capacity of the lithium battery will be enough to keep the clock for ten years. Calendar of the device, which is based on the use of special chip's internal clock, runs until 2099. However, the use of PU at an ambient temperature below $-5^{\circ} \mathrm{C}$ will lead to a significant error related to the violation of the clock, which is caused by a violation of the clock frequency of the internal quartz resonator of the real-time clock chip at low temperatures. The LED display and the keyboard used as part of PU MSMBT allow the students to view and modify the settings of the device, as well as make quick correction in the algorithm of its work. The display and timer keyboard scanning service scan is realized by a processor in a dynamic mode, which can significantly reduce the energy consumption of the device.

Managing the load circuit of PU MSMBT is realized by the use of two special components: power simistor and launching optisimistor. In the PU MSMBT only the optisimistor is used with zero check, and their simistor is shunted by $\mathrm{RC}$ bit game (snubber), which guarantees the elimination of spurious current spikes associated with the phenomenon of self-inductance in snubber with reactive load (e.g., step-up transformers and step-down transformers). Modern electronic components that make up PU MSMBT and tested circuit designs ensure high reliability.

Experimental studies were carried out in 2013-2014. In the first stage the dynamics of students' psychophysiological condition was studied, with the means of rehabilitation techniques of meteobaroconditioning used as primary ones.

We used the following methods:

- pedagogical experiment;

- psychophysiological methods:

- time simple reaction on the sound and the beginning of the movement; 
- $\quad$ time of anticipatory reaction (ACR);

- tremorometry and coordination tests by Meda;

- hands-moving tapping test;

- oculomotor tapping test;

- methods of variation statistics.

The parallel ascertaining experiment was conducted in real-life conditions. From the students of the 2nd year of full-time primary school branch of the Modern Humanitarian Academy (MHA) were formed experimental and control groups (20 in each group).

At the second stage, in several studies related to this integral work the possibility of toning techniques of isotone and meteobaroconditioning were consistently and comparatively analyzed.

It should be noted that the isotone technique developed by V.N. Seluyanov received its name firstly, by the type of exercise, which occupy the central place in the classroom, namely, the isotonic ones i.e. those in which the muscles are constantly strained during a set, and, secondly, by the main effect that is achieved by its application - high "vitality" of a person engaged in isotonic procedure. The central position in the technique is occupied by the isotonic (static-dynamic) exercise which distinguishes isotone from other methods and ensures its high efficiency.

On the other hand, the researches by I.N. Afanasyeva, O.J. Boxer, G.V. Kulago showed that meteobaroprocedures if they are carried out in a pulsed mode, not only reduce meteosensitivity of a person, but also have a tonic effect on the body of the subjected persons.

In the studies, the MHA students also took part who were distributed into 4 groups (one control group and three experimental groups of 20 people in each):

Group 1 - students involved in physical training at the sports complex by programs recommended by the Ministry of Education (the control group);

Group 2 - students involved only in the procedure of meteobarotraining;

Group 3 - students involved only in the isotone procedure;

Group 4 - students involved in the integrated variant combining in each training process the methods of isotone and meteobarotraining. Both techniques were implemented simultaneously inside one and the same meteobarotent operating in a pulse mode (computer-controlled multiseater meteobarotent).

Research methods and the number of sessions were the same as at the first stage of the integral work.

\section{Results of the Research}

Evaluating the efficiency of the selected approach was carried out by comparing the results (in dynamics) of psychophysiological testing of students of the experimental and control groups. The results were received before classes with the help of meteobaroconditioning and physical exercise training, and also after 20 classes, 1-2 classes per week. Each test measurement of simple reaction or CTA (10 measurements in one series of tests) was preceded by three introductory dimensions. The duration of the test and oculomotor hands-moving tapping tests, tremor and coordination tests $-60 \mathrm{sec}$.

Psycho-physiological testing results are shown in Tables 1 and 2. The comparative analysis shows the positive results of the test methodology of meteobaroconditioning.

Table 1. Dynamics of psycho-physiological testing results of the experimental group

\begin{tabular}{|c|c|c|c|c|}
\hline Criteria & Period & $\begin{array}{l}\mathrm{x} \text { (arithmetic } \\
\text { mean) }\end{array}$ & $\begin{array}{c} \pm m \text { (average error } \\
\text { mean) }\end{array}$ & $\begin{array}{l}\mathrm{p} \text { (error probability in the confidence } \\
\text { rating of the differences) }\end{array}$ \\
\hline \multirow{2}{*}{ Simple reaction } & before experiment & 130 & 1,6 & \multirow{2}{*}{ Not enough } \\
\hline & after experiment & 128 & 2,1 & \\
\hline \multirow{2}{*}{ Time of anticipatory reaction } & before experiment & 35 & 1,6 & \multirow{2}{*}{$<0,001$} \\
\hline & after experiment & 28 & 1,4 & \\
\hline \multirow{2}{*}{ Tapping test } & before experiment & 340,4 & 10,00 & \multirow{2}{*}{$<0,05$} \\
\hline & after experiment & 358,6 & 7,45 & \\
\hline \multirow{2}{*}{ Oculomotor tapping test } & before experiment & 61,8 & 1,44 & \multirow{2}{*}{$<0,001$} \\
\hline & after experiment & 69,3 & 1,19 & \\
\hline \multirow{2}{*}{ tremor } & before experiment & 80,3 & 9,67 & \multirow{2}{*}{$<0,05$} \\
\hline & after experiment & 58,5 & 6,74 & \\
\hline \multirow{2}{*}{ Coordination test } & before experiment & 191,2 & 50,57 & \multirow{2}{*}{$<0,05$} \\
\hline & after experiment & 96,3 & 10,86 & \\
\hline
\end{tabular}


Application of the proposed methodology for ascertaining experiment resulted in a statistically significant increase ( $p$ $<0.05$ ) of the psychophysiological state indicators in most tests compared with those obtained before the experiment. The results of the study were processed by the method of variation statistics. The results of psycho-physiological testing achieved by the experimental group using techniques of meteobaroconditioning significantly better than by the control group which were involved in the sports complex training of the program recommended by the Ministry of Education. However, it should be mentioned that the "simple reaction" test proved to be little sensitive. Apparently, in the future it is advisable to implement this test in conjunction with the samples on consecutive negative self-inductance.

Table 2. Dynamics of psycho-physiological testing results of the control group

\begin{tabular}{|l|l|c|c|c|}
\hline Criteria & Period & $\mathrm{X}$ & $\pm \mathrm{m}$ & $\mathrm{P}$ \\
\hline \multirow{2}{*}{ Simple reaction } & before experiment & 126 & 3,5 & \multirow{2}{*}{ not enough } \\
\cline { 2 - 5 } & after experiment & 129 & 2,6 & \\
\hline \multirow{2}{*}{ Time of anticipatory reaction } & before experiment & 34 & 2,1 & \multirow{2}{*}{$<0,05$} \\
\cline { 2 - 5 } & after experiment & 30 & 1,8 & \\
\hline \multirow{2}{*}{ Tapping test } & before experiment & 316,1 & 9,81 & \multirow{2}{*}{$<0,05$} \\
\cline { 2 - 4 } Oculomotor tapping test & after experiment & 335,6 & 9,38 & \\
\hline \multirow{2}{*}{ Tremor } & before experiment & 59 & 1,76 & \multirow{2}{*}{$<0,05$} \\
\cline { 2 - 4 } & after experiment & 62,5 & 2,09 & \multirow{2}{*}{$<0,01$} \\
\hline \multirow{2}{*}{ Coordination test } & before experiment & 76,5 & 7,02 & \\
\cline { 2 - 4 } & after experiment & 59,4 & 7,06 & \multirow{2}{*}{$<0,05$} \\
\hline
\end{tabular}

The study results on the comparative analysis of the tonic possibilities of the physical exercise, isotone and meteobarotraining are presented in Tables 3-6. They show a pronounced impact of health procedures of isotone and meteobarotraining, especially in their complex combination.

Table 3. Dynamics of psycho-physiological testing results of the control group

\begin{tabular}{|l|l|c|c|c|}
\hline Показатели & Период & $\mathrm{x}$ & $\pm \mathrm{m}$ & $\mathrm{p}$ \\
\hline \multirow{3}{*}{ Simple reaction } & before experiment & 138,1 & 2,23 & not enough \\
\cline { 2 - 5 } & after experiment & 140,2 & 1,77 & \\
\hline \multirow{3}{*}{ Time of anticipatory reaction } & before experiment & 38,4 & 3,25 & \multirow{2}{*}{ not enough } \\
\cline { 2 - 5 } & after experiment & 34,5 & 2,72 & \\
\hline \multirow{3}{*}{ Tapping test } & before experiment & 359,0 & 9,06 & \multirow{2}{*}{$<0,05$} \\
\cline { 2 - 5 } & after experiment & 374,5 & 8,57 & \\
\hline \multirow{2}{*}{ Cculomotor tapping test } & before experiment & 55,6 & 2,52 & \multirow{2}{*}{$<0,05$} \\
\cline { 2 - 4 } & after experiment & 59,4 & 1,94 & \\
\hline \multirow{2}{*}{ Tremor } & before experiment & 73,3 & 5,53 & \multirow{2}{*}{$<0,05$} \\
\cline { 2 - 4 } & after experiment & 83,2 & 5,84 & \\
\hline & before experiment & 88,5 & 6,65 & \multirow{2}{*}{$<0,05$} \\
\cline { 2 - 4 } & after experiment & 97,7 & 6,57 & \\
\hline
\end{tabular}

Table 4. Dynamics of psycho-physiological testing results of the control group which used the techniques of meteobaro conditioning

\begin{tabular}{|l|l|c|c|c|}
\hline Criteria & Period & $\mathrm{x}$ & $\pm \mathrm{m}$ & $\mathrm{p}$ \\
\hline Simple reaction & before experiment & 140,2 & 2,52 & $<0,05$ \\
\cline { 2 - 5 } & after experiment & 135,8 & 2,38 & \\
\hline \multirow{2}{*}{ Time of anticipatory reaction } & before experiment & 41,0 & 2,76 & $<0,01$ \\
\cline { 2 - 4 } & after experiment & 32,4 & 2,70 & \\
\hline \multirow{2}{*}{ Tapping test } & before experiment & 355,9 & 5,08 & $<0,05$ \\
\cline { 2 - 4 } & after experiment & 365,1 & 5,15 & \\
\hline \multirow{2}{*}{ Oculomotor tapping test } & before experiment & 59,9 & 2,61 & $<0,001$ \\
\cline { 2 - 4 } & after experiment & 70,1 & 2,33 & \\
\hline Tremor & before experiment & 96,9 & 6,49 & $<0,05$ \\
\cline { 2 - 4 } & after experiment & 85,8 & 6,86 & \\
\hline \multirow{2}{*}{$\begin{array}{l}\text { Coordination test } \\
\text { Simple reaction }\end{array}$} & before experiment & 117,9 & 9,33 & $<0,05$ \\
\cline { 2 - 4 } & after experiment & 101,2 & 8,77 & \\
\hline
\end{tabular}


Table 5. Dynamics of psycho-physiological testing results of the control group which used the isotone technique

\begin{tabular}{|l|l|c|c|c|}
\hline Criteria & Period & $\mathrm{x}$ & $\pm \mathrm{m}$ & $\mathrm{p}$ \\
\hline \multirow{2}{*}{ Simple reaction } & before experiment & 130,5 & 2,46 & \multirow{2}{*}{ не дост. } \\
\cline { 2 - 4 } & after experiment & 133,6 & 3,21 & \\
\hline \multirow{2}{*}{ Time of anticipatory reaction } & before experiment & 39,1 & 0,18 & $<0,001$ \\
\cline { 2 - 4 } & after experiment & 33,3 & 0,14 & \\
\hline \multirow{2}{*}{ Tapping test } & before experiment & 354,2 & 5,26 & \multirow{2}{*}{$<0,01$} \\
\cline { 2 - 4 } & after experiment & 366,8 & 4,29 & \\
\hline \multirow{2}{*}{ Oculomotor tapping test } & before experiment & 65,6 & 1,13 & \multirow{2}{*}{$<0,01$} \\
\cline { 2 - 4 } & after experiment & 71,5 & 1,34 & \\
\hline \multirow{2}{*}{ Tremor } & before experiment & 76,8 & 4,64 & \multirow{2}{*}{$<0,01$} \\
\cline { 2 - 4 } & after experiment & 67,7 & 5,71 & \\
\hline \multirow{2}{*}{ Coordination test } & before experiment & 96,2 & 8,29 & $<0,05$ \\
\cline { 2 - 4 } & after experiment & 75,3 & 9,85 & \\
\hline
\end{tabular}

Table 6. Dynamics of psycho-physiological testing results of the control group which used the techniques of isotone and meteobaroconditioning

\begin{tabular}{|l|l|c|c|c|}
\hline Criteria & Period & $\mathrm{X}$ & $\pm \mathrm{m}$ & $\mathrm{P}$ \\
\hline \multirow{3}{*}{ Simple reaction } & before experiment & 130,7 & 0,23 & $<0,05$ \\
\cline { 2 - 4 } & after experiment & 126,8 & 0,22 & \\
\hline \multirow{3}{*}{ Time of anticipatory reaction } & before experiment & 39,5 & 3,02 & $<0,01$ \\
\cline { 2 - 4 } & after experiment & 31,2 & 2,00 & \\
\hline Tapping test & before experiment & 328,7 & 8,99 & \multirow{2}{*}{$<0,05$} \\
\cline { 2 - 4 } & after experiment & 344,1 & 7,81 & \\
\hline Oculomotor tapping test & before experiment & 58,6 & 1,77 & \multirow{2}{*}{$<0,001$} \\
\cline { 2 - 4 } & after experiment & 64,6 & 1,94 & \\
\hline \multirow{2}{*}{ Tremor } & before experiment & 87,8 & 6,94 & \multirow{2}{*}{$<0,01$} \\
\cline { 2 - 4 } & after experiment & 65,1 & 6,90 & \\
\hline \multirow{2}{*}{ Coordination test } & before experiment & 178,9 & 51,27 & $<0,01$ \\
\cline { 2 - 4 } & after experiment & 75,4 & 8,71 & \\
\hline
\end{tabular}

\section{Discussion}

To a large extent the health of the students related to the living conditions in the family and the organization of educational process at all levels of education. If in the comprehensive educational institution you can still keep in touch with most of the students' parents, as the learning process usually takes place in the place of their residence, it is difficult to do this in the professional educational institution, and sometimes impossible. There are objective reasons (remote residence of parents), and subjective, due to the fact that parents believe that childhood, the child has grown and he alone can be responsible for himself. Physical readiness of modern students do not reach more than $60 \%$ of the relevant indicators of 60s. Physical activity reducing negatively affects the health of children, causes respiratory diseases (18\%), blood circulation diseases (to 35\%), locomotor and muscular system (on 45\%), as well as injuries, including fractures (in 15\%) (Zdorovie detey Rossii kak factor natsionalnoi bezopasnosti, 2015).

Within our experiment, we come to the issue of compensation of the negative impact of harmful factors of the educational environment on the health of students through the use of compensation (recovery) tools and techniques, in particular meteobaroconditioning.

Pulse barotrainings in the mode of daily fluctuations of atmospheric pressure can be applied to the prevention meteorotropic reactions. For the rehabilitation is more preferable the mode of outflow-inflow ventilation, which provides pressure fluctuations in the cabin in range of $\pm 10.0 \mathrm{~mm}$ of mercury. These fluctuations correspond to the sharp fluctuations of atmospheric pressure day to day. However, the top of a particular phase of the oscillation is not achieved within a day, but within 0.5 min. The stay period of student in one of the two diametrically opposite phases (compressiondecompression) is $3 \mathrm{~min}$. The total duration of procedure is $30 \mathrm{~min}$., A course of treatment is 10-15 procedures.

At the same time one-time aperiodic mode of meteobarotraining, called "barovaccination" was developed and well 
established.

In case of confident prediction about the daily sharp vector drop of the atmospheric pressure of a student a few hours before the actual drop in atmospheric pressure is subjected to a 5 minute exposure to artificial drop in atmospheric pressure in the direction of lowering or raising (depending on the forecast). Pressure drop range - $10 \mathrm{~mm}$ of mercury. This prepares the functional systems of the body to the real daily drop in atmospheric pressure. The possibility of using systematic impulse meteobarotraining as a means of preventing colds can be considered as an additional effect. This dosage is a 15-minute exposure to artificial fluctuations in atmospheric pressure ( $\pm 15 \mathrm{~mm}$ of mercury) per week.

Clinical observation of students who received pulse barotrainings in the mode of daily fluctuations in atmospheric pressure have shown their high long-term efficacy, good tolerability of single processes and the entire course of treatment. Meteobarotrainings reduce the number of meteorotropic reactions 2-3 times and enable some patients to completely get rid of the meteotrophic pathology.

The findings of research on the possibilities of isotonic and tonic meteobarotrainings show the pronounced effects of these health improving techniques, especially in their complex combination.

\section{Conclusion}

Undeniable progress of the education system is unfortunately accompanied by the progressive decline of health quality. Under these circumstances a set of measures has to be developed of rather rehabilitation than treatment purpose that will be implemented within the framework of educational institutions, aimed at the rehabilitation of students, medical prevention and formation of culture and the need of preserving and promoting health. One of such methods may be meteobaroconditioning. The experiments conducted have shown its high efficiency; meanwhile, it should be noted that an organism's individual features of response to the pulse barotraining are associated with reactions of the structural and functional mechanisms oriented to the optimal adaptation of various structures functioning without their substantial tension with the development of a long-term adaptation, which ultimately brings about higher organism resistance and more economical response of homeostasis systems. The highest indices are marked in combination of meteobarotraining and isoton procedures, as well as the methods of psycho-regulation (autotraining, biofeedback).

\section{References}

Dimova, A.L. (2012). Effektivnost' primeneniya komplekshoi tekhnologhii fizicheskogo i psikhofiziologhicheskogo ozdorovleniya studentov v protsesse uchebnykh zanyatiy po informatike [Efficiency of using an integrated technology of physical and psychophysiological students rehabilitation during computer science classes]. Fizicheskaya kultura: vospitanie, obrazovanie, trenirovka, № 1, 15-18.

Frazier, K. Negative Impact of Social Networking Sites. [Online] Available: http://socialnetworking.lovetoknow.com/Negative_Impact_of_ Social_Networking_Sites (October 1, 2015).

Karpenko, M.P. (2003). Psikhofiziologhicheskie, organizatsionnie i tekhnicheskie aspekty ozdorovleniya studentov metodami fizicheskoi kultury i meteobarokorrektsii [Psycho-physiological, organizational and technical aspects of the improvement of students' health by methods of physical training and meteobarocorrection]. Monografiya: M.P. Karpenko, O.J. Boxer, A.L.. Dimova. M.: MHA.

Mandrykin, Y.V. (2003). Klinicheskie i psikhologhicheskie aspekty meteochustvitelnosti bolnykh s zabolevaniyami organov krovoobrashcheniya: diagnostika i lechenie, profilaktika i meditsinskaya reabilitatsiya [Clinical and physiological aspects of meteosensitivity patients with diseases of the circulatory system: diagnosis and treatment, prevention and medical rehabilitation]. Dissertaciya doktora med. Nauk. M.

Mukchamedzyanov, I.Sh. (2010). Zdoroviesbereghayushchaya informatsionno-kommunikatsionnaya sreda uchebnogo zavedeniya: problemy i perspektivy razvitiya [Healthprotective, information and communication environment in the educational institutions: problems and prospects of development]. Monografija. Kazan: "Idell-Press".

Zdorovie detey Rossii kak factor natsionalnoi bezopasnosti [Health of Russian children as a factor of national security]. (2015). [Online] Available: http://www.nczd.ru/art12.htm (October 1, 2015).

Robert, I.V. (2008). Teoriya i metodika informatizatsii obrazovaniya (psikhol.-ped. i tekhnol. aspekty) [The theory and techniques of education informatzation (psycho-pedagogical and technological aspects)]. M.: IIO RAO, 2008.

Ryagin, S.N. (2009). Preemstvennost' obshchego i professionalnogo obrazovaniya v usloviyakh sovremennykh sistemnykh izmeneniy [Continuity of comprehensive and professional education in conditions of the contemporary systemic change]. Monografija. M.: Nauka.

Thomée, S., Härenstam, A., Hagberg, M. Computer use and stress, sleep disturbances, and symptoms of depression among young adults - a prospective cohort study [Online] Available: http://link.springer.com/article/10.1186\%2F1471-244X-12-176\#page-1 (October 1, 2015). 
Ulyaeva, L.G. (2013). Meteobarotrenirovka v sisteme psikhofiziologhicheskoi podgotovki sportsmenov [Meteobarotraining in the system of psycho-physiological training of athletes]. Collection of works of the All-Russian scientific-practical conference "Topical problems of the training of athletes and sports teams of Russia in the XXXI Olympic Games in 2016 in Rio de Janeiro (Brazil). M.: O०० "Skyprint", 75-79. 